DOI: $\underline{\text { https://doi.org/10.24867/06KG03Staletovic }}$

\title{
IDENTIFIKACIJA POLJOPRIVREDNIH PARCELA UPOTREBOM GOOGLE EARTH ENGINE
}

\section{IDENTIFICATION OF AGRICULTURAL FILEDS USING GOOGLE EARTH ENGINE}

\author{
Aleksandar Staletović, Fakultet tehničkih nauka, Novi Sad
}

\section{Oblast - GEODEZIJA I GEOMATIKA}

Kratak sadržaj - U ovom radu ispitana je upotrebljivost Google Earth Engine platforme u daljinskoj detekciji kroz analizu satelitskih snimaka. Primenom satelitskih snimaka sa Sentinel-1 i Sentinel-2 platforme izvršena je identifikacija poljoprivrednih parcela.

Ključne riječi: Daljinska detekcija, Sentinel-1, Sentinel2, Google Earth Engine

Abstract - This paper examines the usability of the Google Earth Engine platform in remote sensing through satellite imagery analysi. Using satellite images from the Setntile-1 and Sentinel-2 platforms, agricultural parcels were identified.

Keywords:Remote sensing, Sentinel-1, Sentinel-2, Google Earth Engine

\section{UVOD}

Sa prolaskom vremena i usavršavanjem tehnologija rastu mogućnosti primene rezultata inženjerskih radova a ujedno i očekivanja krajnjih korisnika. Da bi proširio područje svog istraživanja i da bi dobio nove podatke, čovek je morao da primeni nova sredstva i pronađe nove metode. Jedna od takvih metoda koja pruža mogućnosti primene u najrazličitijim oblastima jeste daljinska detekcija. Razvoj tehnologije u ovoj oblasti doveo je do toga da je ona i u oblasti poljoprivrede dostigla veoma visok nivo primene. Klasifikacija poljoprivrednih useva, ocena kvaliteta zemljišta, praćenje promana samo su neke od mogućnosti koje ova metoda pruža u oblasti poljoprivrede. Primenom najsavremenijih metoda daljinska detekcija pruža se i mogućnost identifikacije granica poljoprivrenih parcela primenom satelitskih snimaka.

Kao jedna od osnovnih metoda za detekciju granica poljoprivrednih parcela koristi se upravo daljinska detekcija. Daljinska detekcija predstavlja tehnologiju masovnog prikupljanja geoprostornih podataka putem sistema koji nisu u direktnom fizičkom kontaktu sa ispitivanom pojavom ili objektom (senzori na avionu, satelitu). Daljinska detekcija se koristi za potrebe izrade orto-foto planova i karata na osnovu generisanih satelitskih snimaka za određeno područje.

Pošto je izvorni kod programa otvoren, svako može da ga vidi, menja i prilagodi sopstvenim potrebama.

\section{NAPOMENA:}

Ovaj rad proistekao je iz master rada čiji mentor je bio dr Dušan Jovanović, docent.
U poljoprivredi se daljinska detekcija koristi za širok spektar istraživanja, budući da omogućava brzo prikupljanje velike količine informacija o velikom području, kao i veliki broj senzora različitih konstrukcionih karakteristika, koji omogućavaju identifikaciju, praćenje i analizu biljnih kultura, zemljišta i vodenih površina.Cilj ovog rada je demonstracija upotrebljivost Google Earth Engine platforme za identifikaciju poljoprovrednih parcela. Opisan je postupak analize satelitskih snimaka, postupak klasifikacije i identigikacija granica poljoprivrednih parcela na području opštine Vrbas i opština u njenoj okolini.

\section{DALJINSKA DETEKCIJA}

Daljinska detekcija predstavlja metodu prikupljanja informacija o objektu ili pojavi bez fizičkog kontakta sa njima. Metode daljinske detekcije baziraju se na analizi snimaka Zemljine površine ili pojedinih objekata.

Daljinska detekcija koristi se u mnogim oblastima, uključujući geografiju, poljoprivredu, geodeziju i većinu naučnih disciplina na Zemlji (hidrologija, ekologija, okeanografija, glaciologija, geologija). Ona takođe ima vojne, obaveštajne, komercijalne, ekonomske, planske i humanitarne primene $[2,3]$

\subsection{Evropska svemirska agencija-ESA}

Evropska svemirska agencija (European Space Agency, ESA) je međunarodna organizacija, osnovana 1975. godine, koja se bavi istraživanjem svemira.

ESA je koordinator za evropske civilne svemirske aktivnosti. Posao Evropske svemirske agencije je da koordiniše planiranjem i realizacijom evropskih svemirskih programa. Program je orjentisan ka prikupljanju što više informacija o Zemlji, njenoj neposrednoj okolini u svemiru, našem solarnom sistemu i kosmosu, kao i ka tome da razvija satelitske tehnologije i usluge i da promoviše evropsku industriju.

\subsection{Sentinel-1}

Sentinel-1 satelit obezbeđuje radarsko snimanje zemljišta i okeana, nezavisno od doba dana i vremenskih uslova. Prvi Sentinel-1A satelit lansiran je 3. aprila 2014. u okviru projekta ArianespaceSoyuz.

Platforma Sentinel-1 nosi radar tipa Synthetic Aperture Radar (SAR), koji snima u C-opsegu i koji je izdrađen na osnovu SAR-sistema ESA-e i Kanadske svemirske agencije: ERS-1, ERS-2, Envisat i Radarsat. Kapacitet memorije za smeštanje podataka kod ovog satelita je 1 410 gigabajta, a brzina prenosa informacija na stanice na Zemlji je $520 \mathrm{Mbit} / \mathrm{s}$ [1]. 


\subsection{Sentinel-2}

Sentinel-2 je misija za posmatranje Zemlje koju je razvila ESA u okviru programa Copernicus za obavljanje terestričkih posmatranja u cilju pružanja usluga kao što su monitoring šuma, otkrivanje promena zemljišnih pokrivača i upravljanje prirodnim katastrofama.

Sentinel-2 obezbeđuje multispektralne snimke visoke rezolucije Zemljine površine. Misija se sastoji iz dva satelita koji se nalaze $\mathrm{u}$ istoj orbiti na visini od $786 \mathrm{~km} \mathrm{i}$ pozicionirani su za $180^{\circ}$ jedan od drugog. Sentinel-2A je lansiran 23. juna 2015. godine, a Sentinel-2B 07. marta 2017.

Svaki od satelita Sentinel-2 misije ima optički instrument sposoban da snima u 13 spektralnih opsega: 4 benda na 10 $\mathrm{m}, 6$ bendova na $20 \mathrm{~m}$ i 3 benda na $60 \mathrm{~m}$ prostorne rezolucije. Širina orbitalne trake iznosi $290 \mathrm{~km}$.

\section{GOOGLE EARTH ENGINE}

Google Earth Engine je napredna platforma za geoprostornu obradu zasnovanu na oblaku, dizajnirana uglavnom za analizu podataka o okruženju planetarnih razmera. Kombinuje katalog satelitskog snimanja i geoprostorne skupove podataka, koji korisnicima omogućavaju vizualizaciju, manipulaciju, uređivanje i stvaranje prostornih podataka na jednostavan i brz način. Sadrži širok raspon alata za prostornu manipulaciju koji omogućavaju naučnicima, istraživačima i programerima da otkriju promene, preslikaju trendove i kvantifikuju razlike na Zemljinoj površini.

Mogućnost analize i manipulacije podacima prema potrebama korisnika razlikuju ovu aplikaciju od tradicionalne Google Earth aplikacije. Naučnici i neprofitne kompanije koriste Earth Engine za istraživanje daljinskog ispitivanja, predviđanje epidemije bolesti, upravljanje prirodnim resursima i još mnogo toga. Takođe, studenti mogu pristupiti tim podacima kako bi se pridružili raspravi i postal korisnici tih podataka.

Google Earth Engine okuplja više od 40 godina istoriskih i trenutnih globalnih satelitskih snimaka, zajedno sa alatima i računarskom snagom potrebnom za analizu i čuvanje tog ogromnog skladišta podataka. Kao planetarna platforma za analizu podataka o životnoj sredini, on je neprocenjivo sredstvo za studente da prodube svoje znanje o implikacijama klimatskih promena i puno više.

Google Earth nam omogućuje putovanje, istraživanje i učenje o svetu interakcijom s virtualnim globusom. Možemo pregledavati satelitske snimke, mape, terene, 3D zgrade $\mathrm{i}$ još mnogo toga. $\mathrm{S}$ druge strane, Earth Engine je alat za analizu geoprostornih informacija. Među mnogim drugim analizama možemo analizirati pokrivenost šuma $i$ vode, promene u korišćenju zemljišta ili proceniti zdravlje poljoprivrednih polja.

\section{METODE KLASIFIKACIJE SNIMAKA}

Klasifikacija snimaka predstavlja verovatno i najvažniji korak u analizi snimaka. Klasifikacija predstavlja proces pridodavanja piksela smislenim celinama koje opisuju određene pojave na snimku. Kada govorimo o satelitskim snimcima planete Zemlje, prve pojave se manifestuju kao različiti geografski entiteti (vegetacija, voda, zemlja, izgrađeni objekti i td.). Osnovne metode klasifikovanja snimaka bazirane na piksel paradigm (per-pixel) dele se na: nadgledanu (supervised) klasifikaciju i nenadgledanu (unsupervised) klasifikaciju.

\subsection{Nadgledana klasifikacija}

Pri nadgledanoj klasifikaciji se karakteristični pikseli manuelno smeštaju u odgovarajuću klasu kao “tačni”, tj. referentni pikseli. Ovo je krucijalni deo procesa klasifikacije jer se greške napravljene u ovoj klasifikacionoj fazi kasnije mogu jako odraziti na konačne rezultate klasifikacije. Naprosto, treba svaku klasu obučiti potpuno ispravno kako se ne bi dogodila mešanja između klasa već u baznom delu.

\subsection{Nenadgledana klasifikacija}

Nenadgledana klasifikacija je zasnovana na mogućnosti softvera da spaja piskele sličnih spektralnih svojstava $u$ klastere bez da se programu dostavi obučavajući skup za bilo koju klasu. Kompjuter spaja određene piksele zavisno od odabranog algoritma rada i broja izlaznih klasa. Klasteri se formiraju na osnovu neke od metoda za formiranje klastera (sekvencijalni klastering, statistički klastering, RGB klastering, Iso Data klastering). Kod svake metode nenadgledane klasifikacije se pikseli spajaju na osnovu određenih spektralnih svojstava i predefinisanih pravila spajanja. U ovom radu primenjene su dve metode nenadgledane klasifikacije: weka KMeans klasifikacija i wekaXMeans klasifikacija.

\section{3. weka KMeans}

Metoda KMeans je široko korišćena tehnika klasteriranja koja nastoji da smanji prosečnu kvadratnu udaljenost između piksela $u$ istom klasteru. Pruža dosta veliku tačnost, jednostavna je i brza i vrlo privlačna za korišćenje.

WekaKMeans je postupak nenadgledane klasifikacije snimaka zasnovan na grupisanju piskela istih ili sličnih karakteristika u odgovarajuće klastere odnosno klase. Klasteriranje je podela podataka u slične skupove objekata. Predstavljanje podataka s manje klastera nužno gubi određene sitne detalje, ali postiže pojednostavljenje dok odabri više klastera ce prikazati gotovo sve podatke.Postupak wekaKMeans na platform GEE ima nekolko koraka: Definišemo ulaz, odnosno snimak na kojem pronalazimo klasetere, Postavimo parametre klasteringa, odnsno uslove odabira klastera i grupisanja $\mathrm{u}$ klase, Definišemo oblast koju želimo da klasifikujemo, Primenimo klaster na željenu oblast [4].

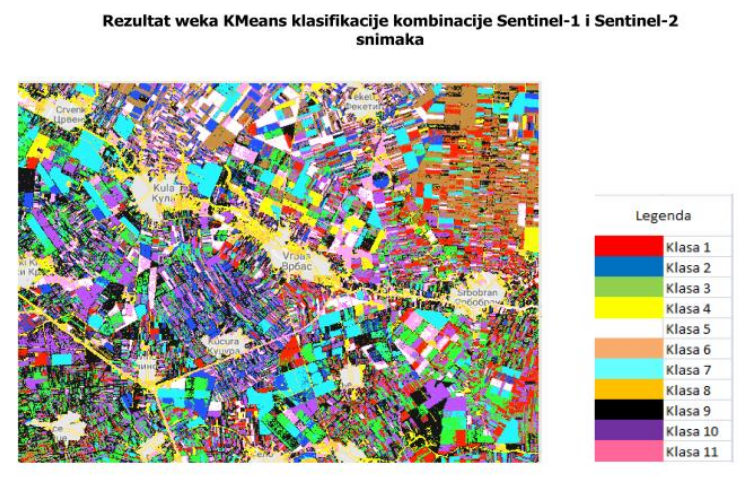

Slika 1. Rezultati weka KMeans klasifikacije 


\section{3. weka Xmeans}

XMeans klastering je veoma sličan KMeans klasteringu. Može se reći da je XMeans u stvari KMeans sa efikasnom procenom broja klastera. Osnovna i jedina razlika između ova dva postupka nenadgledane klasifikacije je to što XMeans pruža mogućnost definisanja minimalnog i maksimalnog broja klastera, dok se kod KMeans-a može podesiti samo ukupan broj klastera. Maksimalan broj klastera u ovoj metodi je 8, dok kod metode Kmeans taj broj može biti mnogo veći [4].

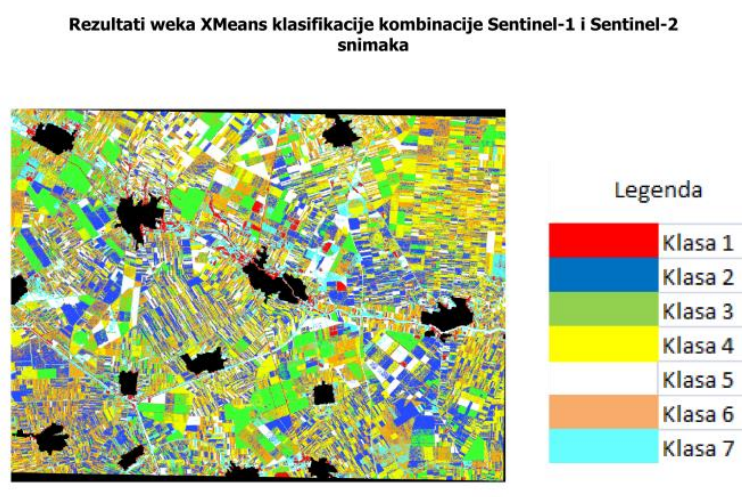

Slika 2. Rezultat weka XMeans klasifikacije

\section{EDGE DETECTION}

Edge Detection odnosno otkrivanje ivica ili detekcija ivica uključuje različite matematičke metode koje imaju za cilj identifikovanje tačaka u digitalnoj slici kod kojih se svetlina slike oštro menja ili, formalnije, ima diskontinuitete. Tačke u kojima se svetlina slike naglo menja, obično se organizuju u skup zakrivljenih segmenata linija nazvanih ivicama.

Isti problem pronalaženja diskontinuiteta u jednodimenzionalnim signalima poznat je pod nazivom detekcija koraka, a problem pronalaženja diskontinuiteta signala tokom vremena poznat je kao detekcija promena. Otkrivanje ivica je osnovno sredstvo u obradi slike, mašinskom i računarskom učenju, posebno u područjima otkrivanja i uklanjanja granica.

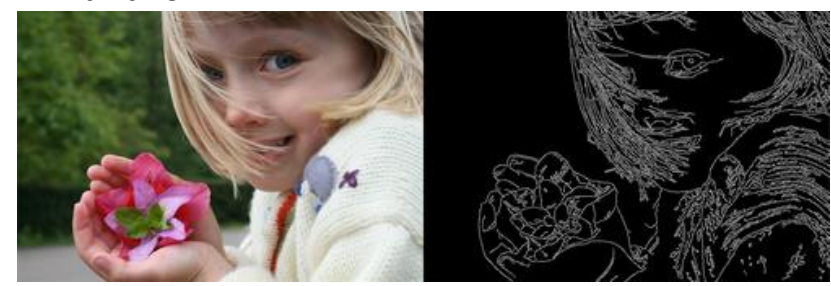

Slika 3. Edge Detection [5]

Važno je napomenuti da detekcija ivica samo ukazuje da je ivica na slici blizu piksela, ali ne daje nužno tačnu procenu lokacije i orijentacije ivice. Greške u detekciji ivica su greške pogrešne klasifikacije: lažne ivice i ivice koje nedostaju. Greške u proceni ivica modelirana je distribucijom verovatnoće za lokaciju i procene orijentacije.

Otkrivanje ivica je značajan proces u računarskoj i digitalnoj obradi slike, tako da je neophodno razmotriti operatore odnosno detektore za otkrivanje ivica. Ivica je brza promena $\mathrm{u}$ intenzitetu piksela slike. Sastoji se od kritične karakteristike i važne karakteristike slike. Takve brze promene otkrivaju se upotrebom derivate prvog reda i derivata drugog reda. Svi ovi derivati bazirani su upotrebi gradijenta.

Gradijent je merilo promene funkcije, i samim tim slika se može smatrati nizom uzoraka nekih kontinualnih funkcija intenziteta slike. Analogno tome, značajne promene $\mathrm{u}$ sivim vrednostima na slici se može otkriti upotrebom diskretne aproksimacije na gradijent.

Ivica je granica između objekta i njegove pozadine. Cilj svakog detektora je da se izbegnu lažne ivice i da otkrivene ivice budu najbliže pravim ivicama. Mnogi detektori ivica razvijeni su u poslednjih dvadeset godina. Neki od operatora za detekciju ivica su: Sobel operator, Laplasian of Gaussian operator, Previtt operator, Robert's cross operator. Najpoznatiji i jedan on najčešće primenjenih operatora, koji daje veoma dobre rezultate $\mathrm{i}$ koji je primenjen u ovom radu je Canny Edge Detection operator [5].

\subsection{Canny Edge Detection operator}

Canny detektor ivica je operator za otkrivanje ivica koji koristi višefazni algoritam za otkrivanje širokog raspona ivica na slikama. Razvio ga je John F. Canny 1986. Među dosada razvijenim metodama otkrivanja ivica, Canny-jev algoritam za otkrivanje ivica je jedna od najstrože definisanih metoda koja omogućava dobru i pouzdanu detekciju. Zahvaljujući svojoj optimalnosti da ispuni sve kriterijuma za detekciju ivica i jednostavnosti postupka za implementaciju, postao je jedan od najpopularnijih algoritama za detekciju ivica.

Canny-ov operator dizajniran je kao optimalan detektor ivica (prema određenim kriterijumima - postoje i drugi detektori koje sam nabrojao koji su takođe optimalni $u$ odnosu na nešto drugačije kriterijume). Kao ulaz uzima sliku, a kao izlaz stvara sliku koja prikazuje položaje praćenih diskontinuiteta intenziteta, odnosno promene vrednosti piksela na osnovu kojih se detektuju ivice $\mathrm{u}$ ovom slučaju granice između klasa.

Zadatak ovog rada bio je detektovanje ivica poljoprivrednih parcela upotrebom Sentinel-1 i Sentinel-2 satelitskih snimaka, ponaosob kao i kombinacijom ova da proizvoda. Da bi se došlo do željenih rezultata pre samog postupka detekcije ivica, odnosno primene algoritma Edge Detection izvršeni su koraci koji podrazumevaju neku vrstu pripreme podataka za detekciju ivica. Ceo postupak analize urađen je na cloud platformi Google Earth Engine i podaci koji su korišćeni za potrebe ovog rada, a to su Sentinel-1 i Sentinel-2 sinimci za period mart-oktobar 2017.godine preuzeti su iz bibloteke same platforme. Budući da su snimci obrađeni, odnosno da su sve metode predprocesinga izvršene na snimcima oni su bili spremni za dalje korišćenje i dalju analizu.

Područje analize, odnosno oblast od interesa nad kojom je sprovedena detaljna analiza u cilju detekcije i identifikacije granica poljoprivrednih parcela jeste deo oko opštine Vrbas i drguh okolnih manjih opština (Srbobran, Kula, Feketić, Mali Iđoš, Temerin, deo Crvenke i mali deo naselja Stepovićevo). Ovaj deo obiluje obradivim poljoprivrednim zemljištem sa velikim brojem poljoprivrednih 
parcela, pa je bio veoma pogodan za primenu algoritma da identifikaciju poljoprovrednih parcela. Cilj rada bio je detekcija granica poljoprivrednih parcela, iz razloga što je veoma čest slučaj da na jednoj katastarskoj parceli vlasnik zasadi više poljoprivredih kultura, pa je poželjno poznavati granicu između njih.

Prvi korak ka identifikaciji poljoprovrednih parcela bio je postupak klasifikacije snimaka. Sentinel-1 i Sentinel-2 snimci klasifikovani su metodama nenadgledane klasifikacije weka KMeans i weka XMeans. Budući da područje analize obuhvata i naseljeni i gradski deo bilo je neophodno izdvojiti taj deo. To je urađeno uvođenjem maske, odnosno maskiranjem gradskog dela, jer nam taj deo nije značajan za dobijanje željenih rezultata. Kao maska korišćeni su podaci sa Corine Land Cover-a koji su takođe dostupni na Google Earth Engine-u.

Izbor nenadgledane klasifikacije leži u tome što nisam imao nikakve ulazne podatke o kulturama na području od interesa koje bih mogao iskoristiti za kreiranje obučavajućih skupova i primenu nadgledane klsifikacije. Sa druge strane primena nenadgledane klasifikacije dala je mogućnost definisanja većeg broja klasa i identifikaciji što većeg broja poljoprivrednih parcela, a samim tim i bolju detekciju ivica, tj. granica parcela. Cilj je bio da se klasifikacijom dobiju podaci koji će omogućiti sto bolju identifikaciju parcela, jer na sirovim snimcima je to znatno teže. Nakon postupka svrstavanja piksela u klase, odnosno postupka klasifikacije, pristupilo se završnom koraku odnnosno identifikaciji poljoprivrednih objekata primenom Canny Edge Detektora. Na sledećim slikama prikazani su dobijeni rezultati.

Canny Edge Detection nakon weka XMeans klasifikacije
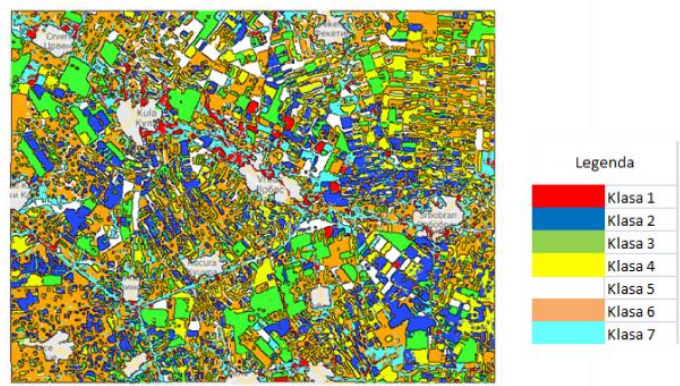

Slika 4. Canny Edge Detection KMeans klasifikacije

Canny Edge Detection nakon weka XMeans klasifikacije
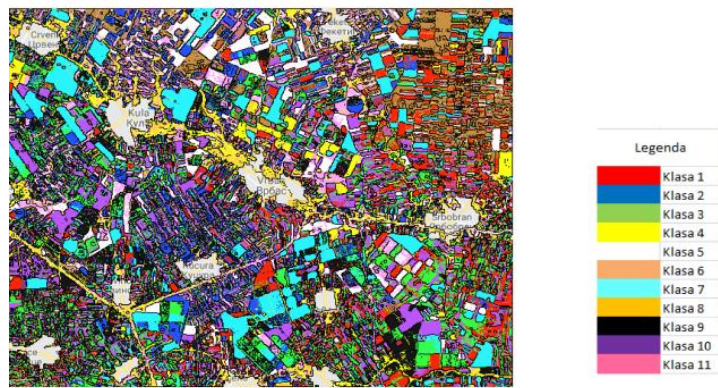

Slika 5. Canny Edge Detection XMeans klasifikacije

\section{ZAKLJUČAK}

Razvoj satelitskih platformi i multispektralnih skenera omogućava sistematičan i veran prikaz područja od interesa. Satelitski snimci pružaju brz i pouzdan izvor raznovrsnih informacija o proizvoljnoj oblasti, koje se koriste u raznim naučnim disciplinama. Brzina prikupljanja podataka je od naročitog značaja u poljoprivredi, šumarstvu i drugim oblastima radi pravovremenog korektivnog delovanja. $\mathrm{Na}$ osnovu podataka dobijenih sa satelitskih platformi, moguće je vršiti identifikovanje, praćenje stanja, analizu, klasifikaciju i definisanje odnosno otkrivanje granica poljoprivrednih parcela.

Brzina prikupljanja podataka je od naročitog značaja u poljoprivredi, šumarstvu i drugim oblastima radi pravovremenog korektivnog delovanja. $\mathrm{Na}$ osnovu podataka dobijenih sa satelitskih platformi, moguće je vršiti identifikovanje, praćenje stanja, analizu, klasifikaciju i definisanje odnosno identifikovanje granica poljoprivrednih parcela.

U ovom radu prikazan je jedan od načina identifikacije poljoprivrednih parcela, upotebom satelitskih snimaka bez njihovog skidanja i predprocesinga koji oduzimaju puno vremena a i resursa računara. Pokazano je da se i na cloud platformi koja je svima dostupna mogu dobiti veoma kvalitetni rezultati.

Iako metode identifikacije poljoprivrednih parcela, opisane u ovom radu daju zadovoljavajuće rezultate, predlaže se dalje istraživanje ovih ali i drugih metoda za identifikaciju kako bi se njima postigli još bolji rezultati.

\section{LITERATURA}

[1] Copernicus-Obsearving the Earth. European Space Agency, http://www.esa.int/Our_Activities/Observing the Earth/Copernicus/Overview4, (datum pristupa:2017-maj-16)

[2] https://cyberleninka.ru/article/v/daljinska-detekcijakao-metod-prikupljanja-podataka-o-prostoru (pristupljeno u septembru 2018.)

[3] Jovanović, D., Daljinska detekcija i računarska obrada slike, Senzori i platforme

[4] wekaKMeans i XMeans : https://www.brandidea.com/kmeans.html

[5] Canny Edge Detection : https://homepages.inf.ed.ac.uk/rbf/HIPR2/canny.htm

\section{Kratka biografija:}

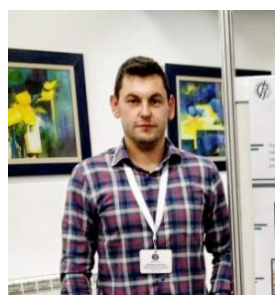

Aleksandar Staletović rođen je u Prištini 1995. godine. Osnovne akademske studije na Fakultetu Tehničkih nauka upisao je 2014. godine a završio 2018. godine. Iste godine upisao je master studije na Fakultetu tehničkih nauka. Oblasti interesovanja su daljinska detekcija, lasersko skeniranje i fotogrametrija.

kontakt: geoaleksandar95@gmail.com 